\author{
Ифатуроти Адебойе Олувасеун \\ Южно-Уральский государственный университет \\ г. Челябинск, Россия \\ deboye@hotmail.co.uk
}

\title{
Краткий очерк типологических особенностей языка йоруба
}

\begin{abstract}
Аннотация
В статье представлен материал по фонетическому и грамматическому строю йоруба - одного из самых распространённых языков западной Африки, который, наряду с формой официального литературного языка, представлен большим количеством диалектных вариантов. С использованием примеров, подобранных автором - носителем языка йоруба - из современного нормативного речевого употребления, в статье показаны способы выражения смыслового содержания и различных грамматических значений и категорий в языке йоруба, строй которого имеет существенные отличия от известных современных языков Европы, принадлежащих как к аналитическому (английский, французский), так и синтетическому (русский) типам. Результаты исследования показали, что, во-первых, лексические значения в языке йоруба могут дифференцироваться посредством изменения высоты используемого тона; во-вторых, при словообразовании используется редупликация и агглютинация; в-третьих, категории времени глагола, определённости / неопределённости имени, сравнительная и превосходная степени прилагательных выражаются лексическими средствами; наконец, синтаксические конструкции в силу нефлективности слова в йоруба, как и в европейских аналитических языках, строятся по фиксированной модели.
\end{abstract}

Ключевые слова: йоруба, языковые тоны, языковое значение, орфография, словообразование, грамматика.

(C) Ифатуроти А. О. 2021

Для цитирования: Ифатуроти А. О. Краткий очерк типологических особенностей языка йоруба // Теоретическая и прикладная лингвистика. 2021. Вып. 7, № 1. С. 74-85. doi: 10.22250/2410-7190_2021_7_1_74_85.

\section{1. Введение [Introduction]}

Язык йоруба принадлежит семейству ква из нигеро-конголезских языков Африки. Он является одним из основных языков Нигерии, и на нём говорят в основном на территории западной части страны. Кроме Нигерии, на йоруба говорят в центральном и восточном регионах Бенина. В состав языка йоруба входят западный, юго-восточный, центральный и северо-восточный диалекты [Oyelaran, 1975, с. 36]. М. Х. Уоткинс, исследуя языки Нигерии, отмечает, что более $80 \%$ населения на западе страны говорят на йоруба. За ним следует язык эдо, носители которого составляют всего лишь 7\% общего населения этого региона [Watkins, 1972, p. 387]. Таким образом, йоруба является самым распространённым языком в Нигерии.

Классификация диалектов йоруба имеет характер «диалектного континуума» на основании того, что эти диалекты обладают высокой степенью «взаимопонятности», хотя между ними наблюдаются фонологические, лексические и даже некоторые грамматические различия. В число диалектов языка йоруба входят игбомина, ондо, иджеша, иболо, ифе, йева, эгба, иджебу, авори, ойо и ибадан. Поскольку язык йоруба существует в различных диалектных разновидностях, возникает вопрос, какой из его диалектных вариантов может послужить материалом для данного исследования. При описании языка йоруба исследователи обычно работают с так называемым стандартным его вариантом, который «используется в целях обучения, общения и контакта между носителями разных диалектов» [Adebisi, Bamgbose, 1980, p.46]. Он развился на основе диалекта 
ойо, но в процессе стандартизации претерпел существенные изменения, в силу чего современный стандартный йоруба настолько сильно отличается от диалекта ойо, что теперь он рассматривается как совершенно самостоятельный вариант языка [Fabunmi, 1970, p. 3-4]. Он является объектом и нашего исследования.

В действительности стандартный йоруба существует главным образом в письменной форме и как своего рода лингва-франка в пределах говорящих на языке йоруба районов. Эта форма считается официальной и престижной, поэтому в общественных местах большинство носителей языка йоруба стремятся использовать именно её и избавиться от диалектных особенностей в своей речи. Таким образом, стандартная форма языка йоруба может рассматриваться как разновидность языка, который используется в преподавании, публичных выступлениях и служит письменным и литературным стандартом для всего языкового сообщества. Международный Африканский институт определяет стандартный вариант языка йоруба следующим образом:

1) на языке йоруба говорят как на родном $20 \%$ нигерийцев;

2) в общей сложности носителями языка в стране являются около $25 \%$ от общей численности населения страны;

3) именно стандартный вариант языка йоруба используется средствами массовой информации, в том числе радио, телевидением и в интернете;

4) стандартный вариант языка йоруба также используется в качестве языка формального обучения в учебных заведениях;

5) для стандартного варианта языка йоруба принята нормативная орфография.

Итак, язык йоруба является одним из наиболее документированных языков в Нигерии. Бельгийский лингвист А. Герард пишет: «пока нигде в Африке не осуществляют литературную деятельность на местном языке с таким интересом и значимой результативностью, как это свойственно представителям интеллигенции йоруба, проявляющих явную исключительную степень способностей к творчеству как на родном, так и на европейских языках» [Gerard, 1982, p. 12].

\section{2. Фонетика и орфография [Phonetics and orthography]}

Алфавит языка йоруба состоит из двадцати пяти букв и пяти диграфов. В йоруба произношение звуков, обозначенных этими буквами, может в некоторой степени отличаться в зависимости от диалекта. Такая вариантность в произношении объясняется тем, что, как уже было отмечено выше, язык йоруба включает около 30 диалектов.

Здесь приведём общие сведения о гласных и согласных стандартной разновидности йоруба. Инвентарь гласных включает 7 неносовых гласных /i e $\varepsilon$ а о $ว$ u/ и 5 носовых /ٓ̃ $\tilde{\varepsilon}$ ã $\tilde{\jmath} \tilde{\mathrm{u}} /$, дифтонгов в системе не представлено [Eme, Uba, 2016, p. 74-75]. Инвентарь согласных включает 18 единиц: /b t d k g kp gb f s $\int \mathrm{h} d \mathrm{~m} \mathrm{n} 1 \mathrm{r} \mathrm{j}$ w/ [Eme, Uba, 2016, p. 74-77].

В лингвистической литературе имеется ряд экспериментальных работ, посвящённых системе гласных фонем йоруба и особенностям их реализации. Так, выявлено, что пары гласных [ео] и [єว] различаются прежде всего по ряду, их разница по подъёму несущественна [Allen et al., 2013]. Также обнаружено, что при выпадении гласного оставшийся гласный подвергается небольшому компенсаторному удлинению [Danis, 2020]. Проведены сравнительно-сопоставительные исследования систем согласных и гласных, например языка йоруба с малайским [Oshodi, 2013], игбо [Eme, Uba, 2016], полезные для изучения данных языков как иностранных.

Йоруба является тональным языком, в котором тон выполняет смыслоразличительную функцию: для различения лексических и грамматических значений используются фонологически значимые тоны. В йоруба три тона, сочетаемость которых в 
пределах слова неограничена [Eme, Uba, 2016, p. 77-78], что нашло отражение в орфографии (см. табл. 1), где имеется большое количество диакритических знаков для гласных а, e, ẹ, i, o, o, u. В зависимости от высоты тона слово может иметь различные значения.

\section{Т а б л и ц а 1. Тоны в языке йоруба \\ [T a b 1 e 1. Lexical tones in Yoruba]}

\begin{tabular}{|c|c|}
\hline Тип тона & Обозначение \\
\hline Высокий тон & á,é,ẹ,í,ó,ọ,ú \\
\hline Средний тон & не отмечается \\
\hline Низкий тон & à,è,è,ì,ò,ọ,ù \\
\hline
\end{tabular}

\author{
ọkọ ‘муж’ \\ ọkọ́ 'тяпка' \\ ọ̀ \\ okọ̀ 'машина'
}

Комментируя значимость тона в языке йоруба, П. Ладефогед подчёркивает важную роль интонации в передаче значения слова и указывает на то, что носители атональных языков испытывают затруднения в понимании изменения значения слова в зависимости от изменения тона [Ladefoged, 1964, p. 26]. Тоновые знаки по правилам ставятся только на гласных. Заметим, что гласные в начальной позиции слова могут иметь только средний и низкий тон и никогда высокий.

Исследованию тонов йоруба посвящены некоторые более поздние работы, например [Ajíbóyè et al., 2011], где изучались особенности реализации тонов при взаимодействии просодии слова и просодии фразы с привязкой к выпадению гласного и гласной вставке.

\section{3. Словообразование [Word building]}

Одной из главных особенностей имён существительных в языке йоруба является почти полное отсутствие односложных существительных, что отличает их от глаголов, которые главным образом существуют в односложных вариантах. Наиболее распространены двусложные и трёхсложные имена существительные, которые всегда начинаются с гласных звуков, за исключением существительных, заимствованных из других языков: kádàrá 'судьба' (заимствовано из арабского языка); bọ̣́̀lù 'мяч' (заимствовано из английского языка), и относительно небольшой группы существительных, образованных способом редупликации, например: kikoó 'учение', lílọ' 'ходьба'. Словообразование имён существительных осуществляется главным образом путём префиксации, агглютинации и редупликации. Что касается префиксации, то наиболее распространёнными продуктивными префиксами имён существительных являются односложные префиксы $a-, e-, e-, i-, o-, o-$, которые образуют от глаголов имена существительные со значением имени действия, деятеля, орудия действия и существительные с абстрактным значением. При помощи префикса $a$ - обычно образуются имена существительные со значением имени действия: àbọ 'приезд' (от $b \grave{o}$ 'приезжать'), àlọ' 'отъезд', (от $l o ̣$ 'уходить'); префиксы $e$ - и е- образуют имена существительные со значением имени действия или результата действия: èbẹ 'просьба' (от bè 'просить'), èșè 'грех', (от șẹ 'грешить'), ęù 'тяжесть' (от rù 'нести', èrò 'мысль') и т. п. Префикс $i$ - очень продуктивный - с его помощью от глаголов образуются имена существительные со значением имени действия и результата действия: irìn 'ходьба', (от rìn 'ходить'), iṣé 'работа', (от șe 'выполнять'), ibẹwò 'посещение' (от bèwò 'посещать') и т. п.

Существительные с абстрактным значением обычно образуются от глаголов качества или состояния: òtútù 'холод' (от tútù 'быть холодным'), òye 'ум' (от ye 'быть умным, талантливым'). Существительные со значением деятеля могут быть образованы 
как от глаголов, так и посредством агглютинации глагола и существительного. Например, ota 'стрелок' (от ta 'пронзать'), ode 'охотник' (от de 'ловить'), orẹ 'друг' (от rẹ 'дружить'), òmòlé 'строитель' ( $\dot{o}+m o$ 'строить' + lé 'дом') и т. п.

Упомянутая выше редупликация не ограничена существительными. В этой связи не может не вызывать интерес просодическая редупликация как способ образования наречий (при обязательном наличии двух мор) [Ehineni, 2017].

Следует особо отметить, что словообразование языка йоруба уже стало предметом разработки автоматического морфологического анализатора, успешно апробированного на материале отглагольных существительных, образованных с помощью аффиксации [Agbeyangi et al., 2016]. Имеются сравнительно-сопоставительные исследования разнообразных словообразовательных моделей, например, с немецким языком [Fabusuyi, Ogunwale, 2015].

\section{4. Грамматика [Grammar]}

\section{1. Морфология [Morphology]}

Имена существительные в языке йоруба имеют предметное значение. В языке йоруба ни существительные, ни местоимения не склоняются. Однако для личных местоимений характерно противопоставление формы прямого падежа формам косвенных падежей, что позволяет нам говорить о супплетивных формах склонения местоимений. В таблице 2 приведены формы личных местоимений в прямом и косвенном падежах:

Т а б л и ц а 2. Личные местоимения

[T a b 1 e 2. Personal pronouns]

\begin{tabular}{|c|c|c|c|c|}
\hline \multirow{2}{*}{} & \multicolumn{2}{|c|}{ Ед. ч. } & \multicolumn{2}{c|}{ Мн. ч. } \\
\cline { 2 - 5 } & Пр. п. & Кос. п. & Пр. п. & Кос. п. \\
\hline 1 л. & èmi (mo) & mi & áwa (a) wa & wa \\
\hline 2 л. & ìwọ (o) & ọ & è̀yin (ẹ) yin & yin \\
\hline 3 л. & òun (ó) & un & àwọn (wọn) wọn & wọn \\
\hline
\end{tabular}

Что касается категории определённости / неопределённости нужно заметить, что в языке йоруба не существует артиклей как грамматических формантов, а значение определённости / неопределённости выражается с помощью числительного kan от слова ookan (рус. 'один') и указательного местоимения náà (рус. 'тот', 'та', 'то'). Эти слова на самом деле не являются артиклями, но их иногда так называют в силу схожей с артиклями функции выражения значения определённости / неопределённости: числительное kan используется в качестве актуализатора имени существительного со значением неопределённости, а указательное местоимение па́à актуализирует значение определённости [Турбина, Ифатуроти, 2020, с. 55].

Категория рода в языке йоруба непосредственно связана с категорией одушевлённости / неодушевлённости. Значение рода актуально только для одушевлённых существительных и выражается различными способами: во-первых, лексически: существуют слова, обозначающие существа определённого пола: bàbá 'отец', ìá 'мать', okùnrin 'мужчина', obìnrin 'женщина', àkùko 'петух', adiẹ 'курица', àgbò 'баран', àgùntàn 'овца' и т. д. Во-вторых, значение рода может быть выражено посредством добавления к смыслообразующему слову (препозитивно, или постпозитивно) слова со значением пола. У имён существительных, обозначающих людей, значение пола / рода передаётся путём постпозитивного присоединения слов okùnrin 'мужчина' или obìnrin 'женщина'. 
Так, если в качестве примера возьмём слово смысле, то 'мальчик' будет обозначен как omo-okùnrin, а 'девочка' - omo-ọinrin. По тому же правилу слово ìránșé 'слуга' приобретает формы iránșé-ọùnrin 'слуга', или ìránșéobìnrin 'служанка' в случае, когда нужно уточнить пол/род. Для имён существительных, обозначающих животных, в качестве «слов-детерминативов» пола / рода используются ako 'самец' или abo 'самка', которые подставляются препозитивно к основному слову, например: ako-ẹsin 'конь', abo-ẹsin 'кобыла' ('самка коня'); ako-màlú 'бык', abomàlú 'корова' ('самка быка') и т. д.

Кроме того, пол/ род (гендерная принадлежность) в языке йоруба может указываться путём агглютинации двух или больше слов: baálé 'муж', (букв. 'мужчина дома'): «bàbá 'отец', 'мужчина' + ilé 'дом'»; iyálé 'жена': «іуá 'мать' + ilé 'дом'»; bàbá-ńlá 'предок': «bàbá 'мужчина' + ńlá 'большой'»; iyá-ńlá 'прародительница': «iyá 'мать' + ńlá 'большой'»; bàbálèrò 'хозяин', 'домовладелец': «bàbá 'мужчина' + ilé 'дом' + èrò 'путешественник'»; iyálèrò 'хозяйка': «iуá 'мать' + ilé 'дом' + èrò 'путешественник'» и т. д.

Что касается категории числа в языке йоруба, то множественное число существительных образуется также агглютинативным способом. Прежде всего с помощью местоимения àwon 'они', или наречия òpọlopò 'много', каждое из которых, как правило, препозитивно к существительному, от которого нужно образовать множественное число. Хотя они взаимозаменяемые, наблюдается тенденция, согласно которой àwọn 'они' используется по преимуществу с одушевлёнными, а òpọlopò 'много' - с неодушевленными существительными. Например:

Dókítà ti dé - 'Врач прибыл'; Awọn dókítà ti dé - 'Врачи прибыли'.

Ilé yiì dára ní kíkọ - 'Это здание красивое'; Opọ̀lopò ilé yii dára ní kíkọ́ - 'Эти здания красивые'.

Множественное число также может образоваться путём редупликации существительного с соединительным союзом àti. Например:

Onísòwò àti onísòwò kì bá ti bá ara wọn wíjọ. Букв.: * 'Торговец и торговец не должны были обмениваться словами между собой'. = 'Торговцы не должны были ссориться между собой'.

В языке йоруба нет словоизменения именных частей речи (существительных, прилагательных, местоимений и числительных) для выражения грамматических категорий числа, рода и падежа. Таким образом, функции падежей выражаются с помощью синтаксиса. Существует несколько способов выражения синтаксических функций существительных. Во-первых, при помощи порядка слов, несвободного в йоруба, где подлежащее всегда препозитивно глаголу-сказуемому. Например:

Akin ko ìwé sí bàbá rẹ. Букв.: *'Акин писать книга на отец его'. = 'Акин написал отцу письмо'.

Имена существительные в функции прямого дополнения всегда ставятся после глагола. Например:

Mo ni ifẹ́ àbúrò mi. Букв.: *'Я имею любовь младший брат мой'. = 'Я люблю младшего моего брата'.

Притяжательное отношение в языке йоруба выражается посредством контактной позиции (позиции примыкания) двух существительных или существительного и местоимения в порядке следования «определяемое-определитель»: вначале наименование того, что принадлежит кому-либо, а после него именование владельца, например:

Owó bàbá. Букв.: *'деньги отец' = 'деньги (свои) отца'; Owó bàbá mi. Букв.: *'деньги отец мой' = 'деньги моего отца'.

Притяжательное отношение может также выражаться при помощи предлога $t i$ 'для', который часто используется с целью передать обладание тем или иным предметом, например: 
İwé yiì jẹ ti Akin. Букв.: *'Книга эта есть для Акин'. = 'Эта книга Акин';

Fìlà yì kì șe ti àbúrò mi. Букв.: *'Шапка эта не есть для брат мой'. = 'Эта шапка не моего брата'.

Именные словосочетания с зависимым прилагательным строятся по модели «определяемое-определитель»:

Omo rere. Букв: *'ребёнок хороший' = 'хороший ребёнок'.

Обращаем внимание на то, что хотя в конструкциях с описательным и притяжательным значением порядок слов одинаковый, их актуализация в речи различается: в конструкциях со значением принадлежности последний слог главного слова удваивается. Например:

Omo-o Rere. Букв: *'ребёнок для Рере' = 'ребёнок Рере', где 'Рере' - имя собственное.

Прилагательные в большинстве случаев являются постпозиционными по отношению к определяемым существительным. Например:

okùnrin kúkurú kan - букв.: *'мужчина невысокий один' = 'один невысокий мужчина';

ilé ńlá kan - букв. *'дом большой один' = 'один большой дом';

okọ pupa mẹta - букв. *'машины красные три' = 'три красные машины' и т. д.

Однако встречаются исключения, при которых прилагательные ставятся перед существительными: прилагательные gbogbo 'все', òpọlopọ 'большое количество', àimoye 'несчётное', как правило, употребляются препозиционно по отношению к именам существительныхм, чтобы подчеркнуть свойство человека или вещи, которое говорящий считает особым, например:

ológbọ́n omo '(очень) умный ребёнок'; ср.: omo ológbọ́n 'умный ребёнок';

onijọghbọn omo '(очень) нашкодивший ребёнок'; ср.: omo oníjọgbọn 'нашкодивший ребёнок';

ako òkúta '(очень) твёрдый камень'; ср.: òkúta ako 'твёрдый камень'.

В языке йоруба нет специальной флективной формы прилагательного для обозначения сравнительной степени, как в русском (большой - больше) или в английском (big - bigger) языках. Сравнительная степень образуется путём добавления к прилагательному глагола $ј u$, который в общем смысле имеет значение 'превзойти'. Однако в случаях его употребления в качестве квази-детерминатива со значением 'больше' или 'очень', он приобретает функцию наречия. Например:

aṣo yi dára ju t’ọhún - букв.: *'ткань этот хорош превзойти тот' = 'эта ткань лучше, чем та';

ibi iṣé mi jìnà ju ibi iṣé yín - букв.: *'место работа мой далеко превзойти место работа ваш' = 'место моей работы дальше вашего';

Ojà wa wọ́n ju ojà yín - букв.: *'товар наш дорого превзойти товар ваш' = 'наш товар дороже вашего' и т. д.

Вместе с тем исследования показали, что ји продолжает сохранять значение и функциональные характеристики глагола, ибо он обязательно присутствует в устойчивых глагольных конструкциях, строящихся по типу инкорпорации, или рамочной конструкции. В частности, глагол ju образует устойчивое сочетание с глаголом lo 'идти' для выражения превосходной степени, а именно, превосходная степень в йоруба выражается с помощью добавления к конструкции сравнительной степени глагола lo:

Dàda ga, Segun ga ju Dàda, Akin ga ju Dàda ati Segun lọ. - Букв: *'Дада высокий, Шегун высокий превзойти Дада, Акин высокий превзойти Дада и Шегун идти' = 'Дада высокий, Шегун выше, Акин самый высокий';

Ojà wa wọ́n, Ojà yín wọ́n ju, Ojà won wọ́n ju ojà awa ati eyín lọ. - Букв: *'Товары наши дорого, товары ваши дорого превзойти, товары их дорого наши и ваши идти' = 'Наши товары дорогие, ваши товары дороже, их товары самые дорогие'. 
Odò Ògùn tóbi, Odò Ògùn tóbi ju odò Oșun, Odò Oyo tóbi ju odò Ògùn ati Odò Oșun lọ. - Букв: * 'Река Огун большой, Река Огун большой превзойти Река Ошун, Река Ойо большой превзойти река Огун больше река Ошун идти'. = 'Река Огун большая, река Огун больше реку Ошун, река Ойо самая большая';

Adé mo ìé ju gbogbo wa lo. - Букв: *'Аде знать книга превзойти все нас идти' = 'Аде учится лучше всех нас'.

В своей работе лингвист Леон Стасен назвал языки, в которых глаголы используются таким образом, «вербальными языками» [Stassen, 1985, p. 178], а нефлективный способ выражения сравнительной и превосходной степеней в йоруба исследователи относят к «лингвистическим Африканизмам» - термин, обозначающий явления, «которые являются общими или частыми в африканских языках, но полностью отсутствуют или редко присутствуют в других языках» [Meeussen, 1975, p. 268].

Настоящее и прошедшее времена образуются одинаково, поскольку в языке йоруба нет специальных форм, указывающих на время:

Mo lo. 'Я иду'; 'Я ходил';

Awa dé. 'Мы возвращаемся'; 'Мы вернулись';

Ó sùn. 'Он спит'; 'Он спал';

O jókò. 'Ты сидишь'; 'Ты сидел';

Из вышеприведённых примеров понятно, что чтобы определить, какое именно время выражено, необходимо обращать внимание на контекст. Будущее время выражается посредством особого временного форманта уі́ò, который в речи обычно сокращается до $\dot{o}$ и $a ́$. Сокращение препозиционного по отношению к глаголу временного форманта yíò > o встречается очень часто. Например:

Ėmi yíò wá lọla; или: Èmi ò wá lọla; или: Èmi á wá lọ̆la - 'Я приду завтра'.

Поскольку настоящее время и прошедшее время могут не различаться формально, в случаях, когда значение настоящего времени необходимо особо подчеркнуть, в речи добавляется формант. Например:

Àwa ń ko ìwé. 'Мы пишем письмо';

$O$ ń ta aṣo. 'Ты продаёшь одежду';

Èyin ń șe ișé. 'Вы работаете'.

Сравним примеры:

Awa ko iwé. 'Мы пишем письмо'; 'Мы писали письмо';

O ta aṣo. 'Ты продаёшь одежду'; 'Ты продал одежду';

Ėyin șe ișé. 'Вы работаете'; 'Вы работали'.

Соотнесение действия с настоящим или прошедшем временем может выражаться лексически с помощью наречий со значением времени lónil 'сегодня', lánàa 'вчера', tẹllẹtẹlè 'раньше', lọ̀la 'завтра', nísisiỳi 'теперь' обычно в поствербальной позиции. Например:

Adé lo lánàá 'Аде ходил вчера'

Adé ń lo nísisiyii 'Аде идёт сейчас'

Adé á lọ lọla 'Аде пойдёт завтра'

В языке йоруба нет страдательного залога, соответственно, активный и пассивный залог не различаются. Это значит, что субъект действия (лицо или предмет) в предложении не может выступать в функции подлежащего, не производя никакого действия, а вместо этого испытывать на себе чьё-либо действие.

Числительные в языке йоруба представляют собой самостоятельную часть речи, которая обозначает число, количество и порядок предметов. Они считаются наиболее сложной частью речи в языке йоруба с учетом принципов образования и структуры. Исследованию числительных посвящена работа О.Бабаринде [Babarinde, 2013, p. 85]. Автор представил следующее описание. Числительные образуются на основе десятичной и двадцатеричной систем, включающих в себя такие математические действия, как сло- 
жение, вычитание и умножение. В пределах первого десятка количественные числительные представляют собой слова с разными корнями.

Числительные второго десятка образуются по принципу сложения или вычитания кроме числительного ogun 'двадцать'. Для того чтобы образовать числительные от одиннадцати до четырнадцати, к числительному èwá 'десять' добавляется соответствующая цифра; от пятнадцати до девятнадцати вычитается соответствующее число из числительного ogun 'двадцать' со значительными фонетическими изменениями в словах.

1 ení (или oókan)
2 èjì
3 è̀ta
4 è̀rin
5 àrún
6 èfà
7 èje
8 ẹ̀jọ
9 ẹ̀sán
10 ẹ̀wá

$$
\begin{aligned}
& 11=10+1 \text { ọ̀kànlá } \\
& 12=10+2 \text { èjilá } \\
& 13=10+3 \text { ẹtàlá } \\
& 14=10+4 \text { è̀rìnlá } \\
& 15=20-5 \text { àrùndínlógún } \\
& 16=20-4 \text { è̀ì̀ndínlógún } \\
& 17=20-3 \text { ẹtaddínlógún } \\
& 18=20-2 \text { èjìdínlógún } \\
& 19=20-1 \text { okàndínlógún } \\
& 20=10+10 \text { ogún }
\end{aligned}
$$

Если возьмём, например, числительное òkànlá 'одиннадцать', то оно представляет собой результат слияния в одно слово числительного oókan, глагола lé 'прибавлять' и числительного èwá 'десять' в то время, как числительные от пятнадцати до девятнадцати образуются путём вычитания из двадцати. Например, èrìndínlógún 'шестнадцать' образуется из числительного èrin 'четыре', глагола dín 'уменьшить' и числительного ogún 'двадцать'. От числа 50 àádọta и дальше встречается ряд аффиксов: àádo-, ogó-/ogo-, ẹ̣ẹ-, egbẹ-, egbẹe-, egbàá- и т. д., которые должны быть использованы и истолкованы правильно, что делает систему числительных в языке йоруба достаточно сложной. Однако, лингвистический анализ показывает, что образование числительных в языке йоруба осуществляется главным образом с помощью таких фонологических приёмов как слияние звуков, выпадение согласных, элизия, ассимиляция и деназализация; в числе морфологических приёмов выделяются префиксация и сокращение. Что касается порядковых числительных, то они образуются от количественных следующим образом: 'первый' èkínni, 'второй' èkejì, 'третий' ẹketa, 'четвёртый' ẹkrin и так далее.

Из служебных частей речи несомненный интерес и споры вызывает слово $(t) a ̀ b i$ [Jelili Adewale, 2017], анализ которого не подтвердил наличия двух функций у данного слова - союза и вопросительного слова. Оказалось, что функция лишь одна - союз, о чём свидетельствует его встречаемость во всех синтаксических позициях.

В завершении обзора морфологии языка йоруба подчеркнём, что несмотря на десятилетия исследовательской работы немалого количества исследователей, окончательный перечень частей речи так и не установлен, что существенно затрудняет обучение данному языку [Jelili Adewale, 2017, p. 13] с использованием аппарата и методов европейской грамматической традиции.

\section{2. Синтаксис [Syntax]}

Порядок слов в предложении в языке йоруба, как было отмечено выше, строго фиксирован, и в простых повествовательных предложениях с именными актантами подлежащим и дополнением - всегда соответствует модели SVO (подлежащее+глагол +дополнение). Например:

Ade ka ìwé. Букв.: * 'Аде считать книга'. 'Аде читал книгу'. 
Подлежащее $A d e$ в этом предложении является именем собственным, $k a$ - глагол-сказуемое 'читать' или 'считать', а ìwé 'книга' - прямое дополнение при глаголе читать. Косвенные дополнения оформляются предложно:

Ó ko ìwé sí bàbá rẹ.. Букв: * 'Он писать письмо к отец свой' = 'Он написал письмо своему отцу';

Ó ra òdòdó fun ìá rẹ Букв: * 'Она купить цветы для матери свой' = 'Она купила своей матери цветы'.

Что касается конструкций с местоимёнными актантами, то порядок слов также всегда соответствует модели SVO, но при этом наблюдается тенденция удвоения последнего гласного глагола с целю обозначения дополнения.

Ó ka ìwé. Букв.: * 'Он читать книга'. = 'Он читал книгу'. $\rightarrow$ Ó ka á. Букв.: * 'Он читать оно'. = 'Он читал её.'

Ó kọ́ ilé Букв.: * 'Он строить дом' = 'Он построил дом'. $\rightarrow$ Ó kọ o Букв.: * 'Он строить его' = 'Он построил его'.

Ó ko ìwé sí bàbá rẹ. Букв: * 'Он писать письмо к отец свой' = 'Он написал письмо своему отцу'. $\rightarrow$ Ó ko ó sí $i$. Букв: * 'Он писать его к он' = 'Он ему это написал'.

Ó ra òdòdó fun ìyá rè Букв: * 'Она купить цветы для матери свой' = 'Она купила своей матери цветы'. $\rightarrow$ Ó ra á fun un Букв: * 'Она купить это для она' = 'Она их ей купила'.

Сложноподчинённые предложения с придаточными относительными строятся по модели «главное-придаточное»:

Omobinrin tó ń korin. 'Девушка, которая поёт'.

\section{6. Заключение [Conclusion]}

Таким образом, язык йоруба принадлежит семейству ква из нигеро-конголезских языков Африки; в его типологических характеристиках выявляются черты, свойственные языкам африканского континента, но редкие, или полностью отсутствующие в языках других семей. На основании отсутствия словоизменения исследователи обычно относят йоруба к языкам изолирующего типа. Однако дать ему такую однозначную типологическую характеристику можно лишь условно в силу того, что лексико-грамматические значения могут выражаться морфонологически (посредством вариации тонов со смыслоразличительной функцией), лексически (для выражения временны́х значений), агглютинативным способом (при обозначении рода / пола и числа имён существительных, при образовании числительных), с помощью квази-детерминативов (при уточнении глагольных времён). Эти системно-структурные особенности языка йоруба, общие для языков африканского континента, существенно отличают его от современных языков Европы, что затрудняет его изучение и описание исследователями-европейцами.

Тем не менее, в грамматике йоруба есть и то, что характерно для европейских языков - это способы актуализации синтаксических значений и синтаксис в целом (фиксированный порядок слов и использование служебной лексики для выражения синтаксических отношений). Такое сходство может быть объяснено, во-первых, нефлективностью имени (как, например, в английском), в связи с чем синтаксические функции именных актантов могут быть обозначены только их позицией в предложении; во-вторых, предположительно, возможным влиянием английского языка на языки коренного населения Нигерии, в силу чего нормативная конструкция предложения в йоруба аналогична инвариантной модели SVO - типовой для предложений с именными актантами в подавляющем большинстве европейских языков и признанной со времён Декарта и грамматики Пор-Рояля универсальной и отражающей «порядок следования мысли». Принципы устройства системы местоимений также обнаруживают морфо-синтаксические сходства с местоименными парадигмами европейских языков, где, как и в йоруба, сохраняются супплетивные формы склонения. 
Перечисленные типологические особенности языка йоруба наводят на мысль о том, что он, пережив бесписьменные времена, придя к стадии кодификации и литературного нормирования, претерпев при этом активное влияние английского языка, пребывает в состоянии поиска новых способов выражения грамматических значений (агглютинация, редупликация, инкорпорация, «проба артикля» для имени) взамен утраченных, ибо, к примеру, факт наличия падежей у местоимений позволяет предположить наличие в прошлом падежных флексий у имён (и у других частей речи). Однако эта и подобные гипотезы могут быть подтверждены только результатами обширных и прицельных исследований языка йоруба, в том числе - диахронических.

\section{Список литературы}

Турбина, Ифатуроти, 2020 - Турбина, О.А., Ифатуроти, А.О. Категория определенности неопределенности в языке йоруба // Вестник Южно-урал. гос. ун-та. 2020. № 2. С. 55-59.

Adebisi, Bamgbose, 1980 - Adebisi A., Bamgbose A. (1980). The changing pattern of bilingualism in Nigeria. // Patterns of bilingualism: selected papers from the RELC (Regional Language Centre) seminar on acquisition of bilingual ability and patterns of bilingualism, with special reference to Southeast Asian contexts, Singapore, April 1979 / ed. by E. A. Afendras. Singapore : Singapore University Press for the SEAMEO Regional Language Centre (RELC). P. 217-237

Agbeyangi et al., 2016 - Morphological Analysis of Standard Yorùbá Nouns / A. O. Agbeyangi, J. O. Odiete, T. A. Lawal, A. B. Olorunlomerue // American Journal of Engineering Research. 2016. Vol. 5. Iss. 6. P. 8-12.

Ajíbóyè et al., 2011 - Disambiguating Yorùbá tones: At the interface between syntax, morphology, phonology and phonetics / O.. Ajíbóyè, R.-M. Déchaine, B. Gick, D. Pulleyblank // Lingua. 2011. Vol. 121(10). P. 1631-1648. doi : https://doi.org/10.1016/j.lingua.2011.05.008.

Allen et al., 2013 - Allen B., Pulleyblank D., Ajíbóyè Ọ. Articulatory mapping of Yoruba vowels: an ultrasound study // Phonology. 2013. Vol.30, Iss. 2. P. 183-210. doi: https://doi.org/10.1017/ S0952675713000110

Babarinde, 2013 - Babarinde O. The Linguistic Analysis of the Structure of the Yoruba Numerals // Journal of Literature, Languages and Linguistics. 2013. Vol. 1. P. 78-88.

Danis N. Yorùbá vowel deletion involves compensatory lengthening: Evidence from phonetics// Stellenbosch Papers in Linguistics Plus. 2020. Vol. 60. P. 1-12. doi: 10.5842/60-0-753.

Ehineni T. O. Prosodic Reduplication in Yorùbá // J. Univers. Lang. 2017. Vol. 18 (2). P. 39-59. doi : https://doi.org/10.22425/jul.2017.18.2.39.

Eme, Uba, 2016 - Eme C. A., Uba E. D. A contrastive study of the phonology of Igbo and Yoruba // Unizik Journal of Arts and Humanities. 2016. Vol. 17, N 1. P. 65-84.

Fabunmi, 1970 - Fabunmi M. A. Yoruba Idioms. Lagos : Pilgrim Books, 1970. 52 p.

Fabusuyi, Ogunwale, 2015 - Fabusuyi A. A., Ogunwale J. A. A Linguistic Analysis of Verbo-nominal Formation Processes in German and Yoruba Languages // Journal of Linguistics and Language in Education. 2015. Vol. 9, N 1. P. 79-97.

Gerard, 1982 - Gerard A. The Linguists' Unacknowledged Progeny: African Literature // South African Journal of African Languages.1982. N 2. P. 12-14.

Jelili Adewale, A. More on the Categorial Status of (T)àbí in Yorùbá Grammar // Journal of Language and Education. 2017. Vol. 3 (2). P. 6-13. doi : 10.17323/2411-7390-2017-3-2-6-13.

Ladefoged, 1964 - Ladefoged P. A Phonetic Study of West African Languages: An AuditoryInstrumental Survey. Cambridge: Cambridge University Press, 1964. 74 p.

Meeussen, 1975 - Meeussen A. E. Tone Typologies for West African Languages // African Language Studies. 1975. Vol. 11. P. 266-271.

Oshodi, 2013 - Oshodi B. A cross-language study of the speech sounds in Yorùbá and Malay: Implications for second language acquisition // Issues in Language Studies. 2013. Vol. 2. N 1. P. 1-12. 
Stassen, 1985 - Stassen L. Comparison and Universal Grammar. Oxford : Blackwell, 1985. 373 p.

Watkins, 1972 - Watkins M. H. Yoruba Phonemes. Studies in Linguistics in Honor of George L. Trager / ed. by M. Estellie Smith. The Hague : Mouton, 1972. P. 387-389.

UDC 81'42

doi: 10.22250/2410-7190_2021_7_1_74_85

\author{
Adeboye Oluwaseun Ifaturoti \\ South Ural State University \\ Chelyabinsk, Russian Federation \\ deboye@hotmail.co.uk
}

\title{
A brief outline of the typological features of the Yoruba language
}

\begin{abstract}
The article presents materials on the phonetic and grammatical structure of Yoruba - one of the most widely spoken languages of West Africa, which, along with its literary form, exists in many dialectical variants. Using examples selected from modern normative speech usage, the author - a native speaker of the Standard Yoruba - demonstrates the ways of expressing semantic content, various grammatical meanings and categories in the Yoruba language, whose structure has significant differences from known modern analytical (English, French) and synthetic (Russian) languages of Europe. The results of the study show that, first, lexical meanings in Yoruba language can be differentiated by changing tone pitch; second, reduplication and agglutination are vital to the process of word formation; third, the categories of verb tense, definiteness / indeterminacy, comparative and superlative adjectives are expressed by lexical means; finally, syntactic constructions due to the non-inflectional nature of words in Yoruba, as in European analytical languages, are constructed according to a fixed model.
\end{abstract}

Keywords: Yoruba, language tones, language meaning, spelling, word formation, grammar.

(C) Ifaturoti A. O. 2021

For citation: Ifaturoti, A. O. (2021). Kratkiy ocherk tipologicheskikh osobennostey yazyka yoruba [A brief outline of the typological features of the Yoruba language]. Teoreticheskaya $i$ prikladnaya lingvistika [Theoretical and Applied Linguistics], 7 (1), 74-85. doi: 10.22250/2410-7190_2021_7_1_74_85.

\section{References}

Turbina, O. A., Ifaturoti, A. O. (2020). Kategoriya opredelennosti neopredelennosti v yazyke yoruba [Category of certainty / uncertainty in the Yoruba language]. Vestnik Yuzhno-ural'skogo gos. un-ta. Ser. Lingvistika [Bulletin of the South Ural State University. Series "Linguistics"], 17 (2), 55-59.

Adebisi, A., Bamgbose A. (1980). The changing pattern of bilingualism in Nigeria. In E. A. Afendras (Ed.), Patterns of bilingualism: selected papers from the RELC (Regional Language Centre) seminar on acquisition of bilingual ability and patterns of bilingualism, with special reference to Southeast Asian contexts, Singapore, April 1979 (pp. 217-237). Singapore: Singapore University Press for the SEAMEO Regional Language Centre (RELC).

Agbeyangi, A. O., Odiete, J. O., Lawal, T. A., Olorunlomerue, A. B. (2016). Morphological Analysis of Standard Yorùbá Nouns. American Journal of Engineering Research, 5 (6), 8-12.

Ajíbóyè, O.., Déchaine, R.-M., Gick, B., Pulleyblank, D. (2011). Disambiguating Yorùbá tones: At the interface between syntax, morphology, phonology and phonetics. Lingua, 121 (10), 1631-1648. doi : https://doi.org/10.1016/j.lingua.2011.05.008.

Allen B., Pulleyblank D., Ajíbóyè O. (2013). Articulatory mapping of Yoruba vowels: an ultrasound study. Phonology, 30 (2), 183-210. doi: https://doi.org/10.1017/S0952675713000110.

Babarinde, O. (2013). The Linguistic Analysis of the Structure of the Yoruba Numerals. Journal of Literature, Languages and Linguistics, 1, 78-88. 
Danis, N. (2020). Yorùbá vowel deletion involves compensatory lengthening: Evidence from phonetics. Stellenbosch Papers in Linguistics Plus, 60, 1-12. doi : 10.5842/60-0-753.

Ehineni, T. O. (2017). Prosodic Reduplication in Yorùbá. J. Univers. Lang., 18 (2), 39-59. doi : https:// doi.org/10.22425/jul.2017.18.2.39.

Eme, C. A., Uba, E. D. (2016). A contrastive study of the phonology of Igbo and Yoruba. Unizik Journal of Arts and Humanities, 17 (1), 65-84.

Fabunmi, M. A. (1970). Yoruba Idioms. Lagos : Pilgrim Books.

Fabusuyi, A. A., Ogunwale, J. A. (2015). A Linguistic Analysis of Verbo-nominal Formation Processes in German and Yoruba Languages. Journal of Linguistics and Language in Education, 9 (1), 79-97.

Gerard, A. (1982). The Linguists' Unacknowledged Progeny: African Literature. South African Journal of African Languages, 2, 12-14.

Jelili Adewale, A. (2017). More on the Categorial Status of (T)àbí in Yorùbá Grammar. Journal of Language and Education, 3 (2), 6-13. doi :10.17323/2411-7390-2017-3-2-6-13.

Ladefoged, P. (1964). A Phonetic Study of West African Languages: An Auditory-Instrumental Survey. Cambridge : Cambridge University Press.

Meeussen, A. E. (1975). Tone Typologies for West African Languages. African Language Studies, 11, 266-271.

Oshodi B. (2013). A cross-language study of the speech sounds in Yorùbá and Malay: Implications for second language acquisition. Issues in Language Studies, 2 (1), 1-12.

Stassen, L. (1985). Comparison and Universal Grammar. Journal of Linguistics Oxford, 23, 178-179.

Watkins, M. H. (1972). Yoruba Phonemes. In M. Estellie Smith (Ed.), Studies in Linguistics in Honor of George L. Trager (pp. 387-389). The Hague : Mouton. 